JCMS

3,1

6

Received 24 March 2019

Revised 15 April 2019

1 May 2019

Accepted 2 May 2019

\section{Sentiment versus mood: a conceptual and empirical investigation}

\author{
Albert Rapp \\ Equity Alpha Traders GmbH, Cologne, Germany
}

\begin{abstract}
Purpose - The purpose of this paper is to investigate whether sentiment and mood, which are distinct theoretical concepts, can also be distinguished empirically.

Design/methodology/approach - Using a sample of German small-cap stocks and linear techniques, the effect of sentiment and mood on short-term abnormal stock return following earnings announcements is tested separately.

Findings - Mood tends to be a positive factor in predicting short-term abnormal stock return, as its biologically based impact uniformly affects the risk aversion of all market participants. Notably, negative mood influences stock return significantly negatively. Sentiment is no factor, however, as its cognitively based impact affects only unsophisticated investors, namely, their cash-flow expectations.

Research limitations/implications - As the sample is restricted to small-cap stocks from a single stock market and only two proxies of sentiment and mood, respectively, are used, the findings should be generalized with caution. Future research might investigate other markets and employ different proxies of sentiment and mood.

Practical implications - Market participants should be aware of the different effect of sentiment and mood on stock return and adjust investment strategies accordingly.

Social implications - As sophisticated investors are likely to profit from the irrational behavior of unsophisticated investors, who are prone to sentiment, the financial literacy of retail investors should be enhanced. Originality/value - This paper is unique in distinguishing between sentiment and mood, both theoretically and empirically. Such distinction was largely ignored by related past research.
\end{abstract}

Keywords Mood, Sentiment, Cognitive bias, Arbitrage, Post-earnings announcement drift (PEAD)

Paper type Research paper

\section{Introduction}

Concepts of behavioral finance tend to describe the judgment and decision making of investors in a more realistic way than normative neoclassical finance (De Bondt et al., 2008). While limits to arbitrage (Shleifer and Vishny, 1997) seem to prevent at least the entire correction of anomalous mispricing, sentiment and mood have been used as behavioral concepts to explain irrational deviations from intrinsic values. Sentiment is associated with investor decision making being affected by cognitive biases (Baker and Wurgler, 2007) and mood is associated with investor decision making being affected by sustained emotional states (Morris, 1989).

Even though sentiment and mood are different concepts from a theoretical perspective, they tended to be mixed up in preceding research. This study differentiates between sentiment and mood, demonstrating that sentiment and mood also have different empirical impact. Using a sample of German small-cap stocks and event study methodology, it is shown that mood is a positive factor in predicting the short-term cumulative abnormal stock return following earnings announcements. In particular, negative mood significantly depresses stock return. By way of contrast, sentiment is not found to be a factor.

\footnotetext{
(C) Albert Rapp. Published in Journal of Capital Markets Studies. Published by Emerald Publishing Limited. This article is published under the Creative Commons Attribution (CC BY 4.0) licence. Anyone may reproduce, distribute, translate and create derivative works of this article (for both commercial and non-commercial purposes), subject to full attribution to the original publication and authors. The full terms of this licence may be seen at http://creativecommons.org/licences/by/4.0/legalcode
}

Journal of Capital Markets Studies Vol. 3 No. 1, 2019 pp. $6-17$

Emerald Publishing Limited 2514-4774 DOI 10.1108/JCMS-03-2019-0014 


\section{Sentiment}

Sentiment is a concept of behavioral finance and refers to the beliefs investors hold regarding an asset's future earnings (Barberis et al., 1998). The vast majority of preceding research suggested that sentiment reflects beliefs that are irrational, that is, inconsistent with the fundamentals (e.g. Baker and Wurgler, 2007; Barberis et al., 1998; Brown and Cliff, 2005).

Sentiment appears to occur due to the cognitive biases of investors (Baker and Wurgler, 2007). For example, while positive sentiment was found to develop following positive stock returns and negative sentiment to develop following negative stock returns (Brown and Cliff, 2004), extrapolation bias (De Bondt, 1993) and reliance on the representativeness heuristic (Kahneman and Tversky, 1972) tend to play a role. Besides being caused by cognitive biases, sentiment itself may cause biased investor behavior (e.g. Brown and Cliff, 2005). As a result of the mutual relationship between cognitive biases and sentiment, prevailing positive or negative sentiment is likely to become amplified.

\subsection{Sentiment proxies}

Past research suggested a variety of sentiment proxies. The sentiment proxies are either indirect and market-based or direct and non-market-based (Brown and Cliff, 2004). The indirect market-based proxies incorporate market data, such as price or volume data (e.g. Baker and Wurgler, 2006), whereas the direct non-market-based proxies refer to expressed opinions (e.g. Lemmon and Portniaguina, 2006). Sentiment proxies can refer to single stocks (e.g. Joseph et al., 2011), certain segments of the stock market (e.g. Jame and Tong, 2014) or the entire stock market (e.g. Massa et al., 1999). While sentiment proxies tend to either relate to retail investor sentiment (Kumar and Lee, 2006) or institutional investor sentiment (Black, 2006), the majority of the sentiment proxies capture the sentiment of retail investors.

\subsection{Sentiment and stock return}

Sentiment can have a substantial effect on the market prices of stocks. In the shorter term, the return of sentiment-prone stocks is positively related to sentiment. Particularly prone to sentiment are stocks that are difficult to arbitrage, including more speculative, more volatile and smaller-capitalization stocks, as well as the stocks of unprofitable, non-dividend-paying, young, growth or distressed companies (Baker and Wurgler, 2007). In the longer term, however, the relationship between sentiment and the return of sentiment-prone stocks is likely to become negative (Brown and Cliff, 2005). The mispricing created by unsophisticated investors in the shorter term is corrected in the longer term, which is consistent with mean reversion in stock prices (Poterba and Summers, 1988).

In contrast to sentiment-prone stocks, the stocks of dividend-paying mature companies, which tend to be less speculative, less volatile and larger in capitalization, are insensitive to changes in sentiment or might even be negatively related to sentiment in the short-term (Baker and Wurgler, 2007). The concept of sentiment beta quantifies the sensitivity of an individual stock's return to changes in sentiment (Glushkov, 2006).

\section{Mood}

Mood is a psychological concept and refers to a mild but persistent emotional state that is usually unrelated to a specific trigger (Morris, 1989). According to the mood-as-information hypothesis (Schwarz and Clore, 1983), mood influences the perception of risks and benefits during judgment and decision making. It appears that individuals in positive mood attach higher probabilities to the positive outcomes of unrelated events and lower probabilities to the negative outcomes of unrelated events whereas the opposite is true for individuals in negative mood (Wright and Bower, 1992). While individuals in positive mood tend to disproportionately focus on positive information, individuals in negative mood tend to disproportionately focus 
JCMS

3,1

on negative information (Isen et al., 1978). Individuals in negative mood also seem to critically analyze all available information whereas individuals in positive mood seem to rely on simplifying heuristics (Schwarz, 1990). The more complex an issue, the more likely it is that prevailing mood influences judgment and decision making (Clore et al., 1994).

\subsection{Mood proxies}

Past research suggested a variety of mood proxies. A few of the proxies are associated with irregular events that influence mood only when they occur, for example, major sports competitions (Schwarz et al., 1987) and daylight saving time changes (Coren, 1996). Other proxies tend to continuously influence mood, such as those associated with the weather (e.g. Cunningham, 1979) and certain biorhythm proxies (e.g. Rosenthal et al., 1984).

\subsection{Mood and stock return}

The psychological insights regarding mood have been applied to financial decision making. Individuals in positive mood appear to exhibit higher financial risk tolerance than individuals in negative mood (Grable and Roszkowski, 2008). While several of the mood proxies have been tested specifically in a financial markets context, positive mood is related to positive short-term stock return and negative mood to negative short-term stock return (e.g. Dichev and Janes, 2003; Hirshleifer and Shumway, 2003; Kamstra et al., 2003). The concept of mood beta quantifies the sensitivity of an individual stock's return to changes in mood (Hirshleifer et al., 2018). The return attributable to mood represents a deviation from fundamental value (Lahav and Meer, 2012), with the effect of mood on stock return resulting from changes in the risk aversion of investors, rather than changes in expected future cash flows (Harding and He, 2016).

\section{Sentiment vs mood - conceptual issues}

From a theoretical perspective, sentiment and mood can be distinguished clearly. While sentiment is a concept of behavioral finance, mood is a concept that originates in psychology. The proxies of sentiment refer to economic variables, such as stock-market data, whereas the proxies of mood refer to non-economic variables, such as weather data. The direction of causation is one-sided for the mood proxies, which may affect stock return but cannot be affected by stock return. For example, it would not be plausible to suggest that the stock return on a given day explains the hours of sunshine on that day. By way of contrast, the sentiment proxies may both affect stock return and be affected by stock return. For example, the opinions expressed in financial social media may not only explain stock return (Chen et al., 2011) but may also be explained by stock return (Rapp, 2016). Furthermore, sentiment can be diametrically opposed for different stocks or different segments of the stock market (Baker and Wurgler, 2007). Mood tends to have a more uniform impact, however, as it affects the general risk aversion of investors, that is, the market-wide discount rate rather than the expected cash flows of a particular stock (Harding and He, 2016). While sentiment arises due to biased cognitive processes of investors (Baker and Wurgler, 2007), mood arises due to biological processes (Rosenthal et al., 1984). It is therefore questionable whether suboptimal judgment and decision making caused by mood can be changed easily. Suboptimal judgment and decision making caused by sentiment, however, appears to be attenuable through learning and experience (Kahneman and Riepe, 1998).

\section{Motivation and hypothesis development}

In spite of the substantial differences between sentiment and mood, most preceding research did not clearly differentiate between these two concepts. While some studies used the terms sentiment and mood interchangeably (e.g. Lux, 2011), others tended to label mood as sentiment. 
For example, Baker and Wurgler (2007) considered mood proxies like day length as proxies of sentiment. Siganos et al. (2014) referred to sentiment although they incorporated Facebook's Gross National Happiness Index, which constitutes a proxy of mood. Finally, Antoniou et al. (2013) defined sentiment by referring to "individual(s) (who), for whatever extraneous reason, feel(s) excessively optimistic or pessimistic about a situation" (p. 4) although this definition also includes the optimism and pessimism that is due to mood rather than sentiment.

Against that background, this study closes a gap and differentiates between sentiment and mood. The effects of sentiment and mood on stock return are analyzed separately. It is hypothesized that sentiment and mood, which are conceptually different from each other, also influence stock return in different ways. Mood is expected to affect both unsophisticated investors and sophisticated investors whereas sentiment is expected to affect only unsophisticated investors. Sophisticated investors are assumed to be immune to the sentiment-related cognitive biases unsophisticated investors are affected by (Kahneman and Riepe, 1998). Sophisticated investors are also assumed to conduct arbitrage transactions that oppose the sentiment-based trades of unsophisticated investors. As a result, the short-term positive relationship between sentiment and the return of sentiment-prone stocks suggested by past research (Baker and Wurgler, 2007) is expected to weaken. The short-term positive relationship between mood and the return of mood-prone stocks (Hirshleifer et al., 2018), however, is not expected to weaken.

\section{Sample and methodology}

While the return of small-cap stocks appears to be particularly susceptible to sentiment (Baker and Wurgler, 2007) and mood (Hirshleifer et al., 2018), this study employs the sample of 50 German small-cap stocks included in the SDAX. In related past research, German small-cap stocks tended to be neglected. The sample period ranges from January 1, 2011 to December 31, 2015.

For examining the relationship between sentiment and short-term stock return as well as mood and short-term stock return, this study analyzes post-earnings announcement drift (PEAD) (Ball and Brown, 1968). PEAD constitutes a lasting market anomaly (Son et al., 2018). This study argues that after the release of quarterly earnings, short-term stock return does not only depend on the earnings surprise, as suggested by past research (Ball and Brown, 1968), but also on sentiment and mood. Short-term cumulative abnormal stock return is expected to be positively predicted not only by the abnormal stock return on the day of the earnings announcement, which is used as a proxy for the direction and size of the earnings surprise (Swart and Hoffman, 2013), but also by the values of the sentiment and mood variables prevailing when earnings are announced. However, only the mood variables are expected to be significant positive predictors.

The daily abnormal stock returns are calculated by way of event study methodology including the market model with an estimation window of 120 days (MacKinlay, 1997). Cumulative abnormal stock return is analyzed over the five trading days following an earnings announcement, first, to ensure a short-term focus and, second, because the majority of PEAD seems to occur during the week following an earnings announcement (Bernard and Thomas, 1989).

Two proxies of sentiment and two proxies of mood are employed for this study. As far as sentiment is concerned, a market-wide non-market-based measure and a stock-specific market-based measure are used. Regarding the former, consumer confidence (Lemmon and Portniaguina, 2006) is chosen and the most recent value of the German GfK consumer confidence index before earnings were announced is incorporated in a consistent fashion. As stock-specific market-based measure, the respective stock's price-book ratio (Baker and Wurgler, 2007) prevailing on the day before earnings were announced is incorporated.
Sentiment versus mood 
JCMS 3,1

As far as the mood proxies are concerned, two continuous mood proxies, namely, day length and lunar phase are employed. Regarding day length, the average actual day length between the earnings-announcement day and the fifth trading day thereafter is incorporated. Using the actual day length is consistent with the psychological research (Rosenthal et al., 1984) even though it is inconsistent with Kamstra et al. (2003), who were criticized for not using the actual day length (Kelly and Meschke, 2010). Regarding the lunar phase, two indicator variables are constructed. One indicates new moon being at most one day away from the period between the earnings-announcement day and the fifth trading day thereafter. The other is constructed alike but indicates proximity to full moon.

To take account of possible asymmetric effects of sentiment and mood on stock return, terciles of the sentiment proxies as well as the mood proxy that represents day length are formed. From a statistical perspective, terciles are fairly consistent with the categorical new-moon variable and the categorical full-moon variable, as these categorical variables indicate either full moon or new moon for approximately one-third of the cases. Cumulative abnormal stock return during the five trading days following an earnings announcement is regressed separately on the highest and lowest tercile of the sentiment proxies, the highest and lowest tercile of the day-length mood proxy and the categorical new-moon and full-moon variable. To control for the direction and size of the earnings surprise, the abnormal stock return on the earnings-announcement day is included as a predictor variable. The following regression models are estimated:

$$
C A R_{t+1} \text { to } t+5=\beta_{0}+\beta_{1}\left(A R_{t}\right)+\beta_{2}\left(C C h_{t}\right)+\varepsilon_{t},
$$

where $C A R$ represents cumulative abnormal stock return; $\beta_{O}$ represents the constant term; $\beta_{1}$ and $\beta_{2}$ represent slope terms; $A R$ represents abnormal stock return; $C C h$ represents the highest tercile of consumer confidence; and $\varepsilon$ represents the error term.

$$
C A R_{t+1} \text { to } t+5=\beta_{0}+\beta_{1}\left(A R_{t}\right)+\beta_{2}\left(C C l_{t}\right)+\varepsilon_{t},
$$

where $\mathrm{CCl}$ represents the lowest tercile of consumer confidence.

$$
C A R_{t+1 \text { to } t+5}=\beta_{0}+\beta_{1}\left(A R_{t}\right)+\beta_{2}\left(P B h_{t}\right)+\varepsilon_{t},
$$

where $P B h$ represents the highest tercile of the price-book ratio.

$$
C A R_{t+1} \text { to } t+5=\beta_{0}+\beta_{1}\left(A R_{t}\right)+\beta_{2}\left(P B l_{t}\right)+\varepsilon_{t},
$$

where $P B l$ represents the lowest tercile of the price-book ratio.

$$
C A R_{t+1 \text { to } t+5}=\beta_{0}+\beta_{1}\left(A R_{t}\right)+\beta_{2}\left(D L h_{t}\right)+\varepsilon_{t},
$$

where $D L h$ represents the highest tercile of average day length.

$$
C A R_{t+1} \text { to } t+5=\beta_{0}+\beta_{1}\left(A R_{t}\right)+\beta_{2}\left(D L l_{t}\right)+\varepsilon_{t},
$$

where $D L l$ represents the lowest tercile of average day length.

$$
C A R_{t+1 \text { to } t+5}=\beta_{0}+\beta_{1}\left(A R_{t}\right)+\beta_{2}\left(N M_{t}\right)+\varepsilon_{t},
$$

where $N M$ represents an indicator variable for new moon.

$$
C A R_{t+1} \text { to } t+5=\beta_{0}+\beta_{1}\left(A R_{t}\right)+\beta_{2}\left(F M_{t}\right)+\varepsilon_{t},
$$

where $F M$ represents an indicator variable for full moon. 
7. Empirical analysis

\subsection{Descriptive statistics}

During the sample period, 648 relevant earnings announcements occurred. 319 of the earnings announcements are positive, 326 are negative and 3 are neutral, as suggested by the abnormal stock return on the day of the earnings announcement. Table I presents descriptive statistics of the collected quantitative data.

\subsection{Regression results}

In each of the regressions, the coefficient of $A R$ is positive and statistically significant at the 1 percent level. The coefficients of the sentiment and mood variables are presented in Table II[1].

As the mood variable $D L l$ holds a negative coefficient that is significant at the 10 percent level and the mood variable $D L h$ holds a positive coefficient that is close to statistical significance at the 10 percent level $(p=0.112)$, further analysis is conducted. The importance of increasing day length for relatively long days and decreasing day length for relatively short days is additionally investigated. According to Palinkas and Houseal (2000), increasing day length positively affects mood and decreasing day length negatively affects mood. No preceding study is known to the author that analyzed increasing day length for relatively long days and decreasing day length for relatively short days in a financial markets context. The following regression models are estimated:

$$
C A R_{t+1} \text { to } t+5=\beta_{0}+\beta_{1}\left(A R_{t}\right)+\beta_{2}\left(D L h i_{t}\right)+\varepsilon_{t},
$$

where DLhi represents the highest tercile of average day length while day length is also increasing.

$$
C A R_{t+1} \text { to } t+5=\beta_{0}+\beta_{1}\left(A R_{t}\right)+\beta_{2}\left(D L l d_{t}\right)+\varepsilon_{t},
$$

where DLld represents the lowest tercile of average day length while day length is also decreasing.

\begin{tabular}{lccc}
\hline Variable & Observations & Mean & SD \\
\hline$C A R$ & 648 & $-0.20 \%$ & $4.59 \%$ \\
$A R$ & 648 & $0.01 \%$ & $3.70 \%$ \\
$C C$ & 537 & $7.34 \mathrm{pts}$ & $1.67 \mathrm{pts}$ \\
$P B$ & 648 & 2.11 & 1.82 \\
$D L$ & 648 & $12.74 \mathrm{~h}$ & $2.69 \mathrm{~h}$
\end{tabular}

Table I.

Descriptive statistics

\begin{tabular}{lccc}
\hline Regression model & Variable & Coefficient & $t$-statistic \\
\hline$(1)$ & $C C h$ & -0.43 & -1.07 \\
$(2)$ & $C C l$ & 0.42 & 0.91 \\
$(3)$ & $P B h$ & 0.04 & 0.11 \\
$(4)$ & $P B l$ & -0.37 & -0.97 \\
$(5)$ & $D L h$ & 0.59 & 1.59 \\
$(6)$ & $D L l$ & -0.64 & $-1.72^{*}$ \\
$(7)$ & $N M$ & -0.16 & -0.45 \\
$(8)$ & $F M$ & -0.41 & -1.09
\end{tabular}

Note: *Indicates significance at 10 percent level

Table II. Regression results 
JCMS 3,1

The results of the additional analysis are presented in Table III. In both regressions, the coefficient of $A R$ is positive and statistically significant at the 1 percent level.

\section{Discussion}

Since the coefficient of $A R$ is significantly positive in each of the regressions, the abnormal stock return on the day of an earnings announcement is a positive factor in predicting cumulative abnormal stock return in the five trading days thereafter. Thus, PEAD is demonstrated to exist for the sample of SDAX stocks. Both the empirical and the economic importance of PEAD were recently documented (Battalio and Mendenhall, 2011). On the other hand, Chordia et al. (2014) did not find evidence of PEAD, arguing that capital markets had become increasingly efficient.

As the coefficients of $C C h$ and $C C l$ as well as $P B h$ and $P B l$ are insignificant, sentiment could not be shown to have a significant effect on the short-term return of sentiment-prone stocks following earnings announcements. The coefficients of $P B h$ and $P B l$ are positive and negative, respectively, as expected whereas the coefficients of $\mathrm{CCh}$ and $\mathrm{CCl}$ are contrary to expectations negative and positive, respectively. Considering the signs of the coefficients of $P B h$ and $P B l$, it appears that the positive impact of stock-specific sentiment on short-term stock return is attenuated by the arbitrage of sophisticated investors as predicted. This finding is consistent with Schmeling (2007), who demonstrated that institutional investors take advantage of the mispricing caused by retail investor sentiment. Since the coefficients of $\mathrm{CCh}$ and $\mathrm{CCl}$ are negative and positive, respectively, albeit insignificant, it might be speculated that the arbitrage activities due to market-wide sentiment are somewhat exaggerated. Besides, since sentiment in contrast to mood directly relates to the irrational earnings expectations of investors, it is plausible to argue that prevailing high (low) sentiment is likely to increase the probability of sentiment-prone investors being negatively surprised (positively surprised) once actual earnings are released. Such negative surprise (positive surprise) would decrease (increase) stock demand and increase (decrease) stock supply, with relatively lower (higher) cumulative abnormal stock return following the earnings-announcement day. Therefore, the short-term positive relationship between sentiment and stock return might not only be attenuated by the arbitrage activities of sophisticated investors but it might even turn negative if unsophisticated investors are surprised and realize that their earnings expectations were unreasonable. Considering the signs of the sentiment variables' coefficients, it appears more likely that unsophisticated investors are surprised when they relied on market-wide sentiment rather than stock-specific sentiment. The finding that sentiment is no significant factor in predicting the short-term return of sentiment-prone stocks is consistent with some preceding research. Brown and Cliff (2004) reported that market-wide sentiment does not predict the weekly abnormal return of small-cap stocks and Tumarkin and Whitelaw (2001) reported that the weekly abnormal return of technology stocks is not predicted by stock-specific sentiment. On the other hand, Lux (2011) showed that market-wide sentiment predicts the weekly return even of blue-chip stocks in Germany and Joseph et al. (2011) showed that stock-specific sentiment predicts the weekly abnormal return of sentiment-prone stocks. While Livnat and Petrovits (2009) and Mian and Sankaraguruswamy (2012) also analyzed sentiment in association with PEAD, both focused on longer-term PEAD. Livnat and Petrovits (2009) employed the sentiment index from Baker and Wurgler (2006, 2007), which reflects indirect market-based

Table III.

Regression results of additional analysis

\begin{tabular}{cccc}
\hline Regression model & Variable & Coefficient & $t$-statistic \\
\hline$(9)$ & DLhi & 0.25 & 0.63 \\
$(10)$ & DLld & -0.82 & $-2.08^{* * *}$
\end{tabular}

Note: **Indicates significance at 5 percent level 
sentiment, and demonstrated that sentiment is a negative factor in predicting cumulative abnormal stock return over the quarter following earnings announcements. By way of contrast, although Mian and Sankaraguruswamy (2012) also used the sentiment index from Baker and Wurgler (2006, 2007), they reported that sentiment is a positive factor in predicting cumulative abnormal stock return over the quarter following earnings announcements.

The coefficients of the mood variables $D L h$ and $D L l$ are positive and negative, respectively, as expected. Particularly $D L l$ indicates certain statistical significance, which implies that relatively short days may be a substantial negative factor in explaining the short-term cumulative abnormal return of mood-prone stocks following earnings announcements. This finding is consistent with Dowling and Lucey (2008), who incorporated the approach of Kamstra et al. (2003) and suggested that SAD is a significant mood proxy with respect to the return of small-cap stocks. On the other hand, Kaustia and Rantapuska (2016) questioned the existence of a positive relationship between day length and stock return although they analyzed investors from Finland, a country where changes in day length throughout the year are more pronounced than in Germany. Even more, Kaustia and Rantapuska (2016) surprisingly found that the propensity of investors from Northern Finland to buy stocks is negatively related to day length. The additional variables $D L h i$ and DLld are positive and negative, respectively, as expected. The coefficient of $D L l d$ is significant at the 5 percent level whereas the coefficient of $D L h i$ is insignificant. Similar to the coefficients that represent actual day length, DLhi and DLld thus hint at a somewhat asymmetric association between day length and short-term stock return. The negative impact of relatively short days whose day length is decreasing is more pronounced than the positive impact of relatively long days whose day length is increasing. Finally, the variables that reflect the lunar phase also show this asymmetric tendency to a certain extent. Although the coefficient of $F M$ is not significant, it is negative as predicted. The coefficient of $N M$ is negative contrary to expectations but less significant. It might be speculated that full moon somehow negatively affects short-term stock return whereas new moon has no impact. This interpretation is consistent with Brahmana et al. (2014), who demonstrated that full moon negatively affects stock return but new moon has no effect on stock return. By way of contrast, Borowski (2015), who analyzed the stock market in Poland, reported that new moon positively affects stock return but full moon has no effect on stock return. According to Yuan et al. (2006), stock return is at least lower around full moon than around new moon.

While the effect of positive mood on stock return tends to be attenuated to a certain extent, the effect of negative mood tends to be persistent. It appears that the impact of investors who are affected by positive mood is arbitraged away to a certain extent by unaffected sophisticated investors. This seems to be the case even though the associated arbitrage transactions involve short sales, which are a limit to arbitrage (Jones and Lamont, 2002). While correcting for the mispricing due to negative mood merely involves purchasing stocks but not engaging in short sales, it appears that sophisticated investors themselves are not immune to negative mood. The biological processes that cause negative mood might be particularly strong and might have a particularly severe impact on individuals, which is consistent with the psychological research (e.g. Mayberg et al., 1999). The finding that negative mood has a more pronounced impact on the short-term return of mood-prone stocks than positive mood is consistent with Edmans et al. (2007), who analyzed the next-day effect of soccer results on investor mood. Finally, DeHaan et al. (2017) also examined mood in association with PEAD. However, they analyzed only negative mood and longer-term PEAD, arguing that negative weather-induced mood leads to reduced investor activity and thus more pronounced PEAD after both positive and negative earnings announcements.

In summary, the results of the data analysis provide support for the hypothesis that the effect of mood on stock return is more pronounced than the effect of sentiment on stock return.
Sentiment versus mood 
JCMS 3,1

The results of the data analysis underline that sentiment and mood do not only represent distinct theoretical concepts but that sentiment and mood can also be distinguished empirically.

\section{Conclusion}

The major contribution of this paper is to demonstrate that sentiment and mood are separate concepts that need to be differentiated from each other, both theoretically and empirically. While sentiment is a concept of behavioral finance and refers to economic variables, mood is a concept of psychology and refers to non-economic variables. Sentiment arises due to biased cognitive processes of investors whereas mood arises due to biological processes. The direction of causation is one-sided for the mood proxies whereas it is mutual for the sentiment proxies. While sentiment can be diametrically opposed for different stocks or different segments of the stock market, mood tends to have more uniform impact.

This paper empirically shows that sentiment is no factor in predicting the short-term abnormal return of small-cap stocks following earnings announcements. It appears that sophisticated investors attenuate the positive impact of sentiment through arbitrage and unsophisticated sentiment-prone investors, whose irrational expectations are probably surprised when earnings are released, influence stock return in the same direction. The financial literacy of retail investors therefore should be enhanced. Moreover, this paper shows that mood tends to be a positive factor in predicting the short-term abnormal return of smallcap stocks following earnings announcements. As opposed to sentiment, mood is more persistent and its impact on stock return is not easily attenuated by arbitrage, which is particularly true for negative mood. Obviously, it is difficult for investors to free from negative mood irrespective of their sophistication. Market participants should adjust their trading strategies to take account of the different effect of sentiment and mood on stock return.

\section{Note}

1. The regression results are qualitatively similar when halves and quartiles are employed instead of terciles. The regression results are also qualitatively similar when terciles are formed on the basis of percentage changes instead of absolute values of consumer confidence and when terciles are formed on the basis of the natural logarithms instead of the actual values of the price-book ratios.

\section{References}

Antoniou, C., Doukas, J.A. and Subrahmanyam, A. (2013), "Cognitive dissonance, sentiment, and momentum”, Journal of Financial and Quantitative Analysis, Vol. 48 No. 1, pp. 245-275.

Baker, M. and Wurgler, J. (2006), "Investor sentiment and the cross-section of stock returns", The Journal of Finance, Vol. 61 No. 4, pp. 1645-1680.

Baker, M. and Wurgler, J. (2007), "Investor sentiment in the stock market", Journal of Economic Perspectives, Vol. 21 No. 2, pp. 129-152.

Ball, R. and Brown, P. (1968), “An empirical evaluation of accounting income numbers”, Journal of Accounting Research, Vol. 6 No. 2, pp. 159-178.

Barberis, N., Shleifer, A. and Vishny, R. (1998), “A model of investor sentiment”, Journal of Financial Economics, Vol. 49 No. 3, pp. 307-343.

Battalio, R.H. and Mendenhall, R.R. (2011), "Post-earnings announcement drift: bounds on profitability for the marginal investor", Financial Review, Vol. 46 No. 4, pp. 513-539.

Bernard, V.L. and Thomas, J.K. (1989), "Post-earnings-announcement drift: delayed price response or risk premium?”, Journal of Accounting Research, Vol. 27, pp. 1-36.

Black, K.H. (2006), "Improving hedge fund risk exposures by hedging equity market volatility, or how the VIX ate my kurtosis", The Journal of Trading, Vol. 1 No. 2, pp. 6-15. 
Borowski, K. (2015), "Moon phases and rates of return of WIG index on the Warsaw stock exchange", International Journal of Economics and Finance, Vol. 7 No. 8, pp. 256-264.

Brahmana, R., Hooy, C.W. and Ahmad, Z. (2014), "Moon phase effect on investor psychology and stock trading performance", International Journal of Social Economics, Vol. 41 No. 3, pp. 182-200.

Brown, G.W. and Cliff, M.T. (2004), "Investor sentiment and the near-term stock market", Journal of Empirical Finance, Vol. 11 No. 1, pp. 1-27.

Brown, G.W. and Cliff, M.T. (2005), "Investor sentiment and asset valuation”, The Journal of Business, Vol. 78 No. 2, pp. 405-440.

Chen, H., De, P., Hu, Y. and Hwang, B.H. (2011), "Customers as advisors: the role of social media in financial markets", working paper, Krannert School of Management, Purdue University, West Lafayette, IN, October 30.

Chordia, T., Subrahmanyam, A. and Tong, Q. (2014), "Have capital market anomalies attenuated in the recent era of high liquidity and trading activity?", Journal of Accounting and Economics, Vol. 58 No. 1, pp. 41-58.

Clore, G.L., Schwarz, N. and Conway, M. (1994), "Affective causes and consequences of social information processing”, in Wyer, R.S. Jr and Srull, T.K. (Eds), Handbook of Social Cognition, Lawrence Erlbaum, Hillsdale, NJ, pp. 323-417.

Coren, S. (1996), "Accidental death and the shift to daylight savings time", Perceptual and Motor Skills, Vol. 83 No. 3, pp. 921-922.

Cunningham, M.R. (1979), "Weather, mood, and helping behavior: quasi experiments with the sunshine Samaritan”, Journal of Personality and Social Psychology, Vol. 37 No. 11, pp. 1947-1956.

De Bondt, W.F.M. (1993), "Betting on trends: intuitive forecasts of financial risk and return", International Journal of Forecasting, Vol. 9 No. 3, pp. 355-371.

De Bondt, W.F.M., Muradoglu, G., Shefrin, H. and Staikouras, S. (2008), "Behavioural finance: quo vadis?”, Journal of Applied Finance, Vol. 19 No. 2, pp. 7-21.

DeHaan, E., Madsen, J. and Piotroski, J.D. (2017), "Do weather-induced moods affect the processing of earnings news?", Journal of Accounting Research, Vol. 55 No. 3, pp. 509-550.

Dichev, I.D. and Janes, T.D. (2003), "Lunar cycle effects in stock returns", The Journal of Private Equity, Vol. 6 No. 4, pp. 8-29.

Dowling, M. and Lucey, B.M. (2008), "Robust global mood influences in equity pricing", Journal of Multinational Financial Management, Vol. 18 No. 2, pp. 145-164.

Edmans, A., Garcia, D. and Norli, Ø. (2007), "Sports sentiment and stock returns", The Journal of Finance, Vol. 62 No. 4, pp. 1967-1998.

Glushkov, D. (2006), "Sentiment beta", working paper, McCombs School of Business, The University of Texas at Austin, Austin, TX, November.

Grable, J.E. and Roszkowski, M.J. (2008), "The influence of mood on the willingness to take financial risks", Journal of Risk Research, Vol. 11 No. 7, pp. 905-923.

Harding, N. and He, W. (2016), "Investor mood and the determinants of stock prices: an experimental analysis", Accounting \& Finance, Vol. 56 No. 2, pp. 445-478.

Hirshleifer, D. and Shumway, T. (2003), "Good day sunshine: stock returns and the weather", The Journal of Finance, Vol. 58 No. 3, pp. 1009-1032.

Hirshleifer, D., Jiang, D. and Meng, Y. (2018), "Mood betas and seasonalities in stock returns", working paper, National Bureau of Economic Research, Cambridge, MA, June.

Isen, A.M., Shalker, T.E., Clark, M. and Karp, L. (1978), "Affect, accessibility of material in memory, and behavior: a cognitive loop?”, Journal of Personality and Social Psychology, Vol. 36 No. 1, pp. 1-12.

Jame, R. and Tong, Q. (2014), "Industry-based style investing”, Journal of Financial Markets, Vol. 19, pp. 110-130.

Jones, C.M. and Lamont, O.A. (2002), "Short-sale constraints and stock returns", Journal of Financial Economics, Vol. 66 Nos 2-3, pp. 207-239. 
JCMS

3,1

Joseph, K., Wintoki, M.B. and Zhang, Z. (2011), "Forecasting abnormal stock returns and trading volume using investor sentiment: evidence from online search", International Journal of Forecasting, Vol. 27 No. 4, pp. 1116-1127.

Kahneman, D. and Riepe, M.W. (1998), "Aspects of investor psychology", The Journal of Portfolio Management, Vol. 24 No. 4, pp. 52-65.

Kahneman, D. and Tversky, A. (1972), "Subjective probability: a judgment of representativeness", Cognitive Psychology, Vol. 3 No. 3, pp. 430-454.

Kamstra, M.J., Kramer, L.A. and Levi, M.D. (2003), "Winter blues: a SAD stock market cycle", American Economic Review, Vol. 93 No. 1, pp. 324-343.

Kaustia, M. and Rantapuska, E. (2016), "Does mood affect trading behavior?", Journal of Financial Markets, Vol. 29, pp. 1-26.

Kelly, P.J. and Meschke, F. (2010), "Sentiment and stock returns: the SAD anomaly revisited", Journal of Banking \& Finance, Vol. 34 No. 6, pp. 1308-1326.

Kumar, A. and Lee, C.M.C. (2006), "Retail investor sentiment and return comovements", The Journal of Finance, Vol. 61 No. 5, pp. 2451-2486.

Lahav, Y. and Meer, S. (2012), "The effect of induced mood on prices in asset markets - experimental evidence”, working paper, Ben-Gurion University of the Negev, Beersheba, May 3.

Lemmon, M. and Portniaguina, E. (2006), "Consumer confidence and asset prices: some empirical evidence”, The Review of Financial Studies, Vol. 19 No. 4, pp. 1499-1529.

Livnat, J. and Petrovits, C. (2009), "Investor sentiment, post-earnings announcement drift, and accruals", working paper, Stern School of Business, New York University, New York, NY, June 24.

Lux, T. (2011), "Sentiment dynamics and stock returns: the case of the German stock market", Empirical Economics, Vol. 41 No. 3, pp. 663-679.

MacKinlay, A.C. (1997), "Event studies in economics and finance", Journal of Economic Literature, Vol. 35 No. 1, pp. 13-39.

Massa, M., Goetzmann, W.N. and Rouwenhorst, K.G. (1999), "Behavioral factors in mutual fund flows", working paper, Yale School of Management, Yale University, New Haven, CT, December.

Mayberg, H.S., Liotti, M., Brannan, S.K., McGinnis, S., Mahurin, R.K., Jerabek, P.A., Silva, J.A., Tekell, J.L., Martin, C.C., Lancaster, J.L. and Fox, P.T. (1999), "Reciprocal limbic-cortical function and negative mood: converging PET findings in depression and normal sadness", American Journal of Psychiatry, Vol. 156 No. 5, pp. 675-682.

Mian, G.M. and Sankaraguruswamy, S. (2012), "Investor sentiment and stock market response to earnings news", The Accounting Review, Vol. 87 No. 4, pp. 1357-1384.

Morris, W.N. (1989), Mood: The Frame of Mind, Springer-Verlag, New York, NY.

Palinkas, L.A. and Houseal, M. (2000), "Stages of change in mood and behavior during a winter in Antarctica", Environment and Behavior, Vol. 32 No. 1, pp. 128-141.

Poterba, J.M. and Summers, L.H. (1988), "Mean reversion in stock prices: evidence and implications", Journal of Financial Economics, Vol. 22 No. 1, pp. 27-59.

Rapp, A. (2016), "Private investor extrapolation bias - evidence through qualitative content analysis (QCA)", Qualitative Research in Financial Markets, Vol. 8 No. 2, pp. 149-167.

Rosenthal, N.E., Sack, D.A., Gillin, J.C., Lewy, A.J., Goodwin, F.K., Davenport, Y., Mueller, P.S., Newsome, D.A. and Wehr, T.A. (1984), "Seasonal affective disorder: a description of the syndrome and preliminary findings with light therapy", Archives of General Psychiatry, Vol. 41 No. 1 , pp. $72-80$.

Schmeling, M. (2007), "Institutional and individual sentiment: smart money and noise trader risk?", International Journal of Forecasting, Vol. 23 No. 1, pp. 127-145.

Schwarz, N. (1990), "Feelings as information: informational and motivational functions of affective states", in Sorrentino, R. and Higgins, E.T. (Eds), Handbook of Motivation and Cognition, Guilford Press, New York, NY, pp. 527-561. 
Schwarz, N. and Clore, G.L. (1983), "Mood, misattribution, and judgments of well-being: informative and directive functions of affective states", Journal of Personality and Social Psychology, Vol. 45 No. 3, pp. 513-523.

Schwarz, N., Strack, F., Kommer, D. and Wagner, D. (1987), "Soccer, rooms, and the quality of your life: mood effects on judgments of satisfaction with life in general and with specific domains", European Journal of Social Psychology, Vol. 17 No. 1, pp. 69-79.

Shleifer, A. and Vishny, R.W. (1997), "The limits of arbitrage", The Journal of Finance, Vol. 52 No. 1, pp. 35-55.

Siganos, A., Vagenas-Nanos, E. and Verwijmeren, P. (2014), "Facebook's daily sentiment and international stock markets", Journal of Economic Behavior \& Organization, Vol. 107 No. B, pp. 730-743.

Son, D.H., Palmon, D. and Yezegel, A. (2018), "The persistence of firm-specific post-earnings announcement returns", Investment Analysts Journal, Vol. 47 No. 1, pp. 31-47.

Swart, D.J. and Hoffman, A.J. (2013), "Analysis of the post-earnings announcement drift anomaly on the JSE”, Investment Analysts Journal, Vol. 42 No. 77, pp. 17-34.

Tumarkin, R. and Whitelaw, R.F. (2001), "News or noise? Internet postings and stock prices", Financial Analysts Journal, Vol. 57 No. 3, pp. 41-51.

Wright, W.F. and Bower, G.H. (1992), "Mood effects on subjective probability assessment", Organizational Behavior and Human Decision Processes, Vol. 52 No. 2, pp. 276-291.

Yuan, K., Zheng, L. and Zhu, Q. (2006), "Are investors moonstruck? Lunar phases and stock returns", Journal of Empirical Finance, Vol. 13 No. 1, pp. 1-23.

\begin{abstract}
About the author
Dr Albert Rapp, having 20 years of experience in proprietary trading and active portfolio management, is Founding Partner at Equity Alpha Traders GmbH in Cologne, Germany. He holds a DBA from the University of Newcastle and is a CFA charterholder. He has published award-winning research on behavioral finance and has been reviewer for Qualitative Research in Financial Markets. Dr Albert Rapp can be contacted at: Albert.Rapp@uon.edu.au
\end{abstract}

For instructions on how to order reprints of this article, please visit our website: 